\title{
DYNAMIC PROPERTIES OF MAGNETORHEOLOGICAL ELASTOMERS BASED ON IRON SAND AND NATURAL RUBBER
}

\author{
Raa Khimi Shuib $^{1 *}$, Kim Louise Pickering ${ }^{1}$ and Brian Richard Mace $^{2}$ \\ ${ }^{1}$ School of Engineering, University of Waikato, Hamilton, 3216, New Zealand \\ ${ }^{2}$ Department of Mechanical Engineering, University of Auckland, Auckland, 1142, New \\ Zealand
}

*Corresponding author: Tel: +64 078384672; email address: klp@waikato.ac.nz

\begin{abstract}
In this study, magnetorheological elastomers (MREs) based on iron sand and natural rubber were prepared. The Taguchi method was employed to investigate the effect of a number of factors, namely, iron sand content, iron sand particle size and applied magnetic field during curing on tan $\delta$ and energy dissipated during cyclic loading. Tan $\delta$ was measured through dynamic mechanical analysis (DMA) over a range of frequency $(0.01-130 \mathrm{~Hz})$, strain amplitude $(0.1-4.5 \%)$, and temperature $\left(-100-50^{\circ} \mathrm{C}\right)$. Energy dissipated was measured using a universal tester under cyclic tensile loading. The data were then statistically analysed to predict the optimal combination of factors and finally experiments were conducted for verification. It was found that the iron sand content had the greatest influence on $\tan \delta$ when measured over a range of frequency as well as energy dissipated during hysteresis tests. However, none of the factors showed significant influence on $\tan \delta$ when measured over a range of strain amplitude. Furthermore, the iron sand content and magnetic field were also found to influence the width of the peak in $\tan \delta$ as a function of temperature. The morphological characteristics of the MREs were also examined using scanning electron microscopy (SEM).
\end{abstract}




\section{INTRODUCTION}

Material with high damping capability is desired from the viewpoint of vibration suppression in structures. Rubber is by far the most commonly used material for damping; here damping relies on the energy absorbed due to viscous flow that occurs during deformation in this viscoelastic material. However, enhancement of damping through rubber modification or rubber selection to increase viscous flow, not surprisingly, generally results in reduction in stiffness and strength ${ }^{1}$. More recently, magnetorheological elastomers (MREs) have been developed such that inclusion of magnetic particles in rubber enables additional damping through magnetic interaction between neighbouring magnetic particles and interfacial damping between the particles and the rubber matrix. Furthermore, damping and stiffness can be varied by application of an applied magnetic field during fabrication or in service. MREs are often referred to as the solid analog of previously developed magnetorheological fluids (MRFs) used in damping of automotive suspensions. In MRFs, magnetic particles are contained within an oil. The main advantage of MREs over MRFs is that particle sedimentation is overcome. Moreover, MREs do not need containers or seals to hold the fluid or prevent leakage ${ }^{2}$. MREs can be utilised for damping, either alone or within a composite structures such as those including steel plates.

MREs can be fabricated to contain a uniform suspension of magnetic particles (isotropic MREs). However, it has been found that when a magnetic field is applied during curing, chainlike structures of magnetic particles are formed within the rubber (which become anisotropic MREs) which provides much larger damping and stiffness ${ }^{3}$. Figure 1 shows structure of isotropic and anisotropic MREs. Formation of such chain-like structures relies on the mechanism such that when individual particles are exposed to an applied magnetic field, magnetic dipole moments pointing along the field direction are induced within them. A magnetic force will cause the north pole of one particle to attract the south pole of its neighbour resulting in formation of chains and columnar structures inside the matrix. Upon curing the matrix, the particle structure is set in place ${ }^{4}$.

The magnetic particles of choice for MREs are iron particles and suitable matrix materials include natural rubber, silicone rubber, polybutadiene, polyisobutylene, polyisoprene, and 
polyurethene rubber ${ }^{3,5-10}$. These materials are nonmagnetic viscoelastic materials into which the magnetic particles can be added and subsequently processed into a final solid form through conventional rubber or plastic processing ${ }^{11-13}$. Recent work has focused on carbonyl iron and natural rubber MRE because of their associated ease of processing and good damping performance ${ }^{14-16}$. However, one of the biggest challenges in developing MREs is cost. Carbonyl iron particles, the most commonly used particles, are expensive at $\$ 13-15 / \mathrm{kg}$ in bulk. More cheaply produced iron particles, iron oxide $\left(\mathrm{Fe}_{3} \mathrm{O}_{4}\right)$ and barium ferrite $\left(\mathrm{BaFe}_{12} \mathrm{O}_{19}\right)$ tend to be irregular in shape, have wider size distributions, and simply do not perform as well ${ }^{17,18}$. Some iron alloy particles actually perform better than carbonyl iron, but are significantly more expensive ${ }^{19}$. It is apparent that more applications would quickly become commercially viable if the material cost could be reduced.

This work aims to fabricate iron sand and natural rubber MREs. Iron sand was chosen because it has high permeability and saturation magnetisation, low cost, and is readily available in New Zealand. It is derived from erosion of andesitic and rhyolitic volcanic rocks which are the main types of iron ore deposits in New Zealand. Iron sand is a dark, high-density sand that occurs along the west coast of the North Island from Wanganui to Kaipara Harbour near Auckland, over a distance of $480 \mathrm{~km}$. It contains titanomagnetite, a mineral itself containing iron and titanium, which is highly magnetic ${ }^{20,21}$.

The conventional approach of experimental design such that one factor is varied while keeping the remaining factors constant is expensive and time-consuming. Hence, several Design of Experiment (DOE) methods have been developed which can reduce the number of experiments, time, and cost required to model the response function ${ }^{22}$. Among them, the Taguchi method has had great success in designing and optimising the controllable factors to achieve a high quality product or process ${ }^{23,24}$. This method has been used successfully, for example, to optimise the processing conditions and chemical formulation in rubber ${ }^{25,26}$. As far as the authors are aware, there is no published analysis of the factors effecting the dynamic properties of MREs using the Taguchi method. In this study, the loss tangent, commonly called $\tan \delta$, is considered as the fundamental parameter to assess damping. Tan $\delta$ gives a comparison of the energy lost to that 
stored; it is obtained by dividing the loss modulus $\left(\mathrm{G}^{\prime \prime}\right.$ or $\left.\mathrm{E}^{\prime \prime}\right)$ by the storage modulus $\left(\mathrm{G}^{\prime} \text { or } \mathrm{E}^{\prime}\right)^{1}$. Yet, another estimate of damping used in the literature is the amount of energy dissipated during cyclic deformation, which can be calculated from the area of the hysteresis loop. In the next section the Taguchi method is briefly reviewed. Then, the experimental methods used to fabricate the MREs, the factors investigated and the characterisation methods are described. This is followed by a presentation of the results and discussion. Finally, the conclusions are summarised and some finding remarks made.

\section{The Taguchi Method}

The Taguchi method, pioneered by Genichi Taguchi, provides a simple, efficient, and systematic approach to study the effects of multiple variables by identifying the performance trend for each factor and determining the combination that yields optimum conditions.

The Taguchi method generally includes the following steps: (1) identification of the factors and their levels; (2) selection of an appropriate orthogonal array (OA) and assignment of the factors and levels to the OA; (3) conducting of the experiment; (4) analysis of experimental data and determination of the optimal levels; (5) verification of the optimum design factors through experiment.

The key component in designing the experiment is the identification of factors and their levels. With the finalised factors and levels, the Taguchi method makes use of an OA for experimental design. The Taguchi method allows for 18 different standards of OAs and the details of OA selection are published in references ${ }^{24,27}$. After OA selection, experiments are carried out and results can then be analysed using signal-to- noise $(\mathrm{S} / \mathrm{N})$ ratio to determine the effect of each factor and the level that maximizes the performance. The $\mathrm{S} / \mathrm{N}$ ratio can be divided into three categories depending on the desired output performance: nominal (used where a target value is desired), smaller-the-better and larger-the-better, for which Equations 1, 2 and 3 are used respectively to determine $\mathrm{S} / \mathrm{N}$ :

$$
\frac{S}{N}=-10 \log \frac{\sum_{i=0}^{n}\left(Y_{i} \mathrm{M}\right)^{2}}{n}
$$




$$
\begin{aligned}
& \frac{S}{N}=-10 \log \frac{\sum_{i=0}^{n} Y_{\mathrm{i}}^{2}}{n} \\
& \frac{S}{N}=-10 \log \frac{\sum_{i=0}^{n}\left(\frac{1}{Y_{\mathrm{i}}^{2}}\right)}{n}
\end{aligned}
$$

where $\mathrm{M}$ is the average of observed data, $n$ is the number of observation, $i$ is the level and $Y_{i}$ is the observed data at level $i$. Another function of $\mathrm{S} / \mathrm{N}$ is that it is able to determine the ranking of factors by calculating the average effect of a factor at a level. This is given by simple statistical calculation as follows ${ }^{25}$

$$
A j=\frac{\sum_{i=0}^{n}\left(\frac{S}{N}\right) i}{n}
$$

where $A_{j}$ is the average for factor $j,(\mathrm{~S} / \mathrm{N})_{i}$ represents the $\mathrm{S} / \mathrm{N}$ observation of a factor at level $i$, and $n$ represents the total number of observations for that factor. By plotting the average factor effect against the corresponding factor level, a main effect plot is obtained and the trend of the influence of each factor on the results is extracted. The relative effects of factors affecting the response can be calculated by analysis of variance (ANOVA). ANOVA is a powerful statistical analysis tool that can be used in the Taguchi method to determine statistically significant factors and to explore the relative contribution of each factor and level to the total variation. ANOVA provides information on sum of squares, degrees of freedom, percentage confidence level and percentage contribution. The sum of squares is a measure of the total variability of observed data. The sum of squares is defined as

$$
S S=\frac{\sum_{i=0}^{n} X_{a}^{2}}{n}-\frac{T^{2}}{N}
$$

where SS is the sum of squares, $n$ is the number of observations, $a$ is the factor, $X_{a}$ is the sum of observed data at factor $a, \mathrm{~T}=\Sigma \mathrm{X}_{\mathrm{a}}$ is the sum of all data and $\mathrm{N}$ is the total number of data points. The degrees of freedom represents the number of levels for each factor that may vary independently and equals the number of levels of each factor minus one. The percentage 
confidence level represents the probability of the occurrence and the reliability of the data. The percentage contribution can is given by

$$
\text { Percentage contribution }=\frac{S S_{a}}{S S_{T}} \times 100 \%
$$

where $S S_{a}$ is the sum of squares of factor a and $S S_{T}$ is the total sum of squares. With $\mathrm{S} / \mathrm{N}$ ratio and ANOVA analyses, the optimal combination of the factors can be predicted and finally, an experiment can be conducted to verify the optimal factors.

\section{METHOD AND SAMPLE PREPARATION}

\section{Materials}

A fixed masterbatch formulation for rubber was used in this study (Table 1). Natural rubber (SMR L grade) and other chemicals including zinc oxide, stearic acid, n-cyclohexyl-2-benzothiazole sulfenamide (CBS), tetramethylthiuram disulphide (TMTD), paraffin oil, and naphthenic oil were all purchased from Field Rubber Limited, Auckland. Iron sand was collected from Ngarunui Beach, Raglan. The iron sand was then milled using a planetary mono mill (Pulverisette 6) produced by Fristech GmbH and subsequently sieved to obtain a wide range of particle size fractions.

\section{Experimental Design}

\section{Selection of factors and levels}

In this study, three factors were considered: iron sand content, particle size and applied magnetic field during curing. These factors were varied at five levels as shown in Table 2, based on the existing literature $3,4,9,14,16$.

\section{Selection of orthogonal array and analysis of data}

Given the three factors and five levels considered in this study, an L25 orthogonal array (OA) was selected for the Taguchi method. The L25 OA is shown in Table 3 and consists of 25 experiments corresponding to 25 rows and three design factors assigned to the respective columns along with their levels. Analysis of the $\mathrm{S} / \mathrm{N}$ ratio was subsequently used to evaluate the experimental results. In the present study, since the $\tan \delta$ and amount of energy dissipated (hysteresis tests) were intended to be maximized, the larger-the-better target for $\mathrm{S} / \mathrm{N}$ ratio was 
chosen. Analysis of variance (ANOVA) was used to statistically assess the percentage contribution and relationship between each factor. ANOVA was performed by using STATISTICA software.

\section{Preparation of iron sand-natural rubber MREs}

Formulations were determined according to the OA and were compounded using a conventional laboratory two roll mill (model XK150) according to ASTM designation D3184-80. Nip gap (distance between front and back roller), time of compounding and sequence of addition of the ingredients (in the sequence rubber, activator, plasticiser, filler, accelerator and crosslinking agent) were kept constant for all the compounds. The cure time at $150^{\circ} \mathrm{C}$ was then determined according to the procedure as described in reference ${ }^{28}$. Compounded rubber samples weighing $13 \mathrm{~g}$ were placed in a mould $60 \times 50 \mathrm{~mm}$. The isotropic MREs were cured in a compression moulder at $150^{\circ} \mathrm{C}$ under a pressure of approximately $12 \mathrm{MPa}$. The anisotropic MREs were subjected to an external magnetic field in a specially developed electromagnetic-thermal coupled device (as shown in Figure 2) at $80^{\circ} \mathrm{C}$ for 30 minutes and subsequently were cured in a compression moulder at $150^{\circ} \mathrm{C}$ under a pressure of approximately $12 \mathrm{MPa}$. Finally, post-cure treatment was performed by cooling the anisotropic MREs at room temperature for 30 minutes under an external magnetic field of the same strength as that used during pre-curing. The postcure treatment is necessary to reorientate the magnetic dipoles orientation after being exposed to the compression stress during compression moulding.

\section{Characterisation}

\section{Dynamic mechanical analysis}

Dynamic mechanical analysis was carried out using a Perkin Elmer Dynamic Mechanical Analyser (DMA 8000). Tan $\delta$ was measured over a wide range of frequency, strain amplitude and temperature. The influence of frequency and strain amplitude on $\tan \delta$ was assessed using two circular disc specimens with a diameter of $10 \mathrm{~mm}$ and a thickness of $3 \mathrm{~mm}$ in shear mode at room temperature. Tan $\delta$ was measured over the frequency range of $0.01-130 \mathrm{~Hz}$ at a fixed strain amplitude of $0.5 \%$ and over a strain amplitude range of $0.1-4.5 \%$ at a fixed frequency of $100 \mathrm{~Hz}$. 
For the influence of temperature on $\tan \delta$, the samples were analysed in dual cantilever mode at a frequency of $1 \mathrm{~Hz}$, with a strain amplitude of $0.5 \%$ and over a temperature range from $-100-50$ ${ }^{\circ} \mathrm{C}$. The samples were then heated at rate of $2{ }^{\circ} \mathrm{C} / \mathrm{min}$. The samples were rectangular with dimensions $30 \mathrm{~mm} \times 6 \mathrm{~mm} \times 3 \mathrm{~mm}$.

\section{Hysteresis}

Hysteresis loss is defined as the amount of energy dissipated during cyclic deformation when the samples are stretched and then allowed to retract at the same rate to the unstretched state. In this study, the hysteresis loss was determined on tensile dumbbells using an Instron 4204 at a crosshead speed of $500 \mathrm{~mm} / \mathrm{min}$ according to ASTM D412-80. The stress-strain curve was recorded and hysteresis loss was calculated as

Hysteresis loss = Area under the loading curve - Area under the recovery curve

\section{Morphology}

The microstructures of isotropic and anisotropic MREs were observed using a Hitachi S-4700 scanning electron microscope (SEM). The samples were cut into pieces with a surface area of $5 \mathrm{~mm} \times 3 \mathrm{~mm}$ and coated with a thin layer of platinum prior to observation at an accelerating voltage of $20 \mathrm{kV}$.

\section{RESULTS AND DISCUSSION}

The trends obtained in this work were similar to typical trends in previous works for the influence of frequency ${ }^{14,29,30}$, strain amplitude ${ }^{16,31}$ and temperature ${ }^{32,33}$ on $\tan \delta$ as well as the hysteresis loop obtained after a complete reversed stress cycle ${ }^{34,35}$. In order to calculate the optimum levels for the different factors using $\mathrm{S} / \mathrm{N}$ ratio and ANOVA, reference points for $\tan \delta$ were selected. For optimising $\tan \delta$ over a range of frequency of $0.01-130 \mathrm{~Hz}$, the maximum value of $\tan \delta$ was taken as the reference point, which was consistently observed at $130 \mathrm{~Hz}$ (the maximum frequency applied). For optimising $\tan \delta$ over a range of strain amplitude (0.1-4.5\%), the reference point was chosen to be within the plateau region at 3\% strain amplitude. With respect to choosing a reference point over a range of temperature, attention was given to the peak of the curve of $\tan \delta$ versus temperature which represents the glass transition temperature $\left(T_{g}\right)$ where the 
material undergoes drastic changes in the mechanical energy of the molecular vibrational motion. Addition of particulate fillers into rubber is generally not expected to change the temperature at which $\tan \delta$ reaches a peak. What is commonly apparent, however, is broadening of the transition region after $\mathrm{T}_{\mathrm{g}}$ to the plateau region ${ }^{32,36}$. In this study, $\mathrm{T}_{\mathrm{g}}$ of natural rubber is $-47^{\circ} \mathrm{C}$ and the transition region after $\mathrm{T}_{\mathrm{g}}$ to the plateau region was observed at $-47-0{ }^{\circ} \mathrm{C}$. To reflect the broadening of the peak, a reference point for $\tan \delta$ was selected at $-35^{\circ} \mathrm{C}$. In hysteresis testing, the amount of energy dissipated was calculated from the area of the hysteresis loop. Table 4 shows the values of $\tan \delta$ and hysteresis loss obtained for these reference points that were subsequently used to calculate $\mathrm{S} / \mathrm{N}$ ratios and ANOVA, each value representing an average from 3 samples. The highest values for each test type are shown in bold.

\section{Morphology}

Figure 3 shows SEM images of the isotopic and anisotropic MREs. From the SEM micrographs, it can be seen that isotropic MREs have a homogeneous iron sand particle distribution in the rubber matrix without obvious aggregation (Figure 3 a). Figure 3 b-e show anisotropic MREs cured at different magnetic field. Clearly, as expected, applying a magnetic field at elevated temperature allowed the iron sand particles to organise into chain-like columnar structures. It can also be noted that the chains became longer and more aligned as the magnetic field strength increased. A higher magnification micrograph (Figure $3 \mathrm{f}$ ) highlights that there are obvious gaps between iron sand particle and rubber, which suggests weak interaction between iron sand and rubber.

\section{Effect of frequency on $\tan \delta$}

The trends for influence of frequency on $\tan \delta$ when the factors were varied over their different levels are shown on the main effect plots in Figure 4. As discussed earlier, the higher the value of the $\mathrm{S} / \mathrm{N}$ ratio, the better the signal, which implied that the highest value in the main effect plots can be used as the conditions to attain optimised $\tan \delta$. The $\mathrm{S} / \mathrm{N}$ ratio increases with increasing iron sand content until it reaches a maximum value at $70 \mathrm{phr}$ and thereafter decreases at the highest iron sand content (100 phr). The increase of S/N ratio with increasing iron sand 
content can be explained by the increase in energy absorbed due to interfacial friction caused by the increase in interfacial area with increase in iron sand content. The decrease in $\mathrm{S} / \mathrm{N}$ ratio at the highest iron sand content can be explained by poor dispersion of iron sand particles due to the insufficient amounts of rubber matrix to wet the iron sand thoroughly. Similar findings have been observed in other studies ${ }^{15,37}$. From Figures 4 (b) and (c), it can be seen that the particle size and magnetic field had a minimal influences on $\mathrm{S} / \mathrm{N}$ ratio but the $\mathrm{S} / \mathrm{N}$ ratios at $45-56 \mu \mathrm{m}$ and 300 $\mathrm{mT}$ are the highest. The minimal influence of magnetic field on $\mathrm{S} / \mathrm{N}$ ratios would appear to be due to minimal increase of particle separation as the test was performed at a low fixed strain amplitude $(0.5 \%)$ in shear mode such that particle chains would generally rotate rather than extend. The results suggest that the highest value for $\tan \delta$ might be obtained by using $70 \mathrm{phr}$ iron sand, a 45-56 $\mu \mathrm{m}$ particle size and a $300 \mathrm{mT}$ magnetic field during curing.

Table 5 shows ANOVA results for the effect of frequency on $\tan \delta$. It can be seen from the level of contribution that iron sand content has the greatest influence on $\tan \delta$ with a $99.9 \%$ confidence level. The particle size and magnetic field show much less influence (lower \% contribution) with confidence levels of $99 \%$ and $97 \%$, respectively.

The final and essential step to complete the Taguchi analysis, namely conducting an experiment to verify the suggested optimum conditions, was carried out using optimised conditions (70 phr iron sand, 45-56 $\mu \mathrm{m}$ particle size and $300 \mathrm{mT}$ ) and the value of $\tan \delta$ found (0.22) was indeed higher than the highest value achieved previously ( 0.171 for sample type 15$)$. This supports the optimum conditions suggested by $\mathrm{S} / \mathrm{N}$ ratio and ANOVA. The variation of tan $\delta$ with frequency is shown in Figure 5a. Tan $\delta$ is higher for the optimised sample over the whole frequency range explored. $\mathrm{G}^{\prime}$ and $\mathrm{G}^{\prime \prime}$ are also plotted in Figure 5 (b and c) to help highlight the mechanisms involved. $\mathrm{G}^{\prime}$ and $\mathrm{G}^{\prime \prime}$, similar to $\tan \delta$ are frequency dependent and it can be seen that the increase of $\tan \delta$ as the frequency increases is mainly due to increasing in $\mathrm{G}^{\prime \prime}$ as opposed to $\mathrm{G}^{\prime}$. The increase in $\mathrm{G}^{\prime \prime}$ can again be explained by the increased energy loss due to the increase of interfacial friction between the iron sand and rubber with increasing frequency.

\section{Effect of strain amplitude on $\tan \delta$}


Figure 6 shows the main effect plots of the $\mathrm{S} / \mathrm{N}$ ratios for the influence of strain amplitude on $\tan \delta$. The highest $\mathrm{S} / \mathrm{N}$ ratios are observed at $30 \mathrm{phr}$ iron sand content, 56-75 $\mu \mathrm{m}$ particle size and $500 \mathrm{mT}$ magnetic field during curing. However, no obvious trend of the $\mathrm{S} / \mathrm{N}$ ratios is seen for any factor as the level changes. This could be attributed to the poor bonding between iron sand and rubber as supported by morphology. This is in agreement with the results reported by other researchers ${ }^{37}$. The weak interaction between the iron sand and natural rubber is fully disrupted at low strain amplitude and therefore, at high strain amplitude, the damping is dominated by the viscous flow of the rubber matrix. As is the case for the selected reference point ( $3 \%$ strain amplitude) here, it should also be noted that the suggested optimum conditions are different compared with the optimum conditions for the effect of frequency on $\tan \delta(70 \mathrm{phr}, 45-56 \mu \mathrm{m}$, $300 \mathrm{mT}$ ). A lower optimum iron sand content (30phr) supports that at the reference point for the experiment on effect of strain amplitude on tan $\delta$, energy absorbed is more dominated by the viscous flow in rubber matrix. However, the suggested optimum magnetic field is higher, which indicates that formation of longer particle chains opposed the higher shearing force with increasing strain amplitudes such that the particle chain orientation changes and transform elastic energy into magnetic energy, which then dissipates by magnetic hysteresis ${ }^{6,38}$.

Table 6 shows ANOVA results for the effect of strain amplitude on $\tan \delta$. Also seen that the variability for each factor was tested at $99.9 \%$ confidence level. None of the factors have a significant influence on $\tan \delta$ and hence the percentage contribution is approximately the same for each factor.

As expected, an experiment using optimised conditions (30 phr iron sand content, 56-75 $\mu \mathrm{m}$ particle size and $500 \mathrm{mT})$ results in slightly higher value of $\tan \delta(0.160)$ compared with the highest achieved previously ( 0.155 for sample type 15$)$. Figure 7 shows $\tan \delta$, the storage modulus $\left(\mathrm{G}^{\prime}\right)$ and the loss modulus $\left(\mathrm{G}^{\prime \prime}\right)$ of the optimised sample and sample type 15 over a range of strain amplitude (0.1-4.5\%). It was found that $\tan \delta$ and $\mathrm{G}^{\prime}$ were amplitude dependent at low strain amplitudes reaching a plateau at about $1 \%$ strain amplitude. The amplitude dependence at low strain is typically attributed to the Payne effect ${ }^{39}$. This effect is frequently explained by the breakdown of filler aggregates to release trapped rubber to allow more viscous flow, separation 
of dipole-dipole interaction between neighbouring particle and filler rubber detachment and reformation that increases with increasing strain amplitude. Once the strain amplitude is high enough, all the interactions are destroyed to such an extent that it cannot be reconstructed and the Payne effect diminishes. Consequently, the energy loss is largely reliant on the rubber matrix.

\section{Effect of temperature on $\tan \delta$}

The main effect plots of the S/N ratios for influence of temperature on tan $\delta$ are depicted in Figure 8. The Taguchi method suggests that an optimised value for $\tan \delta$ could be obtained by using $30 \mathrm{phr}$ of iron sand content, a 32-45 $\mu \mathrm{m}$ of particle size and a $1000 \mathrm{mT}$ magnetic field during curing. As can be seen from Figure 8 (a), S/N ratios of the filled compounds are higher compared to those of the unfilled compound. Addition of iron sand has constrained rubber chains and therefore increased the temperature required for their mobility, thus increasing relaxation at the reference temperature ${ }^{36}$. From Figure 8 (b), it can be seen that the $\mathrm{S} / \mathrm{N}$ ratios decrease with increasing particle size, which is likely to be due to the decrease of surface area of iron sand adhered to rubber. In Figure 8 (c), the $\mathrm{S} / \mathrm{N}$ ratio increases with increasing magnetic field until it reaches a maximum at $1000 \mathrm{mT}$. This indicates that the formation of magnetic particle chains and columnar structures provides additional damping by further restriction of the intermolecular conformational changes during relaxation, as supported by morphology. As can also be noted, the suggested optimum conditions are different compared with those observed previously for the effect of frequency and strain amplitude on $\tan \delta$. As this test was performed in dual cantilever mode at a fixed low frequency $(1 \mathrm{~Hz})$ and strain amplitude $(0.5 \%)$ over the temperature range, the deformation of material would be much lower compared with that tested in shear loading. Therefore, at selected reference point used for this experiment, the additional damping through interfacial friction and magnetic particle interaction would be expected to be much lower. A lower optimum iron sand content (30phr) supports that the damping is largely reliant on the intermolecular relaxation of the rubber matrix. However, the suggested optimum magnetic field at $1000 \mathrm{mT}$ suggests that the energy absorbed by formation of longer particles chains would not be due to separation of dipole-dipole interaction, perhaps the longer particle chains provide 
additional damping by further restriction of the intermolecular conformational changes during relaxation.

Table 7 shows ANOVA results for the effect of temperature on $\tan \delta$. Iron sand content and magnetic field both show a significant influence on $\tan \delta$ with confidence levels of $99 \%$. It is also apparent that the particle size has much less influence with less than $10 \%$ contribution.

Finally, an experiment was carried out to compare the value of $\tan \delta$ for the optimised sample (30 phr of iron sand content, 32-45 $\mu \mathrm{m}$ particle size and $1000 \mathrm{mT}$ ) with those achieved previously for the sample with the highest value of $\tan \delta$ in the transition zone (sample type 17). In addition, unfilled natural rubber was included for comparison (see Figure 9). The values of tan $\delta$ for the optimised sample, sample type 17 and unfilled natural rubber are 1.280, 1.216 and 0.803 , respectively. As can also be seen, the tan $\delta$ peak of natural rubber is higher compared to the optimised sample and sample type 17. It should be noted, however, that the width of the $\tan \delta$ peaks for the optimised sample and sample type 17 are wider and $\tan \delta$ for the optimised sample at $-35^{\circ} \mathrm{C}$ is the highest. This can again be explained as being due to confinement of molecular chain movement. Since rubber materials are always in practice used in the rubbery phase, the performance and behaviour of the materials in the temperature range after the transition region is more crucial. In the rubbery phase (occurring in the plateau after the peak), it can also be seen that the optimised sample has the largest value of $\tan \delta$, followed by sample type 17 and unfilled natural rubber. This is because at higher temperature the thermal energy is comparable to the potential energy barriers for the viscous flow, therefore, interfacial friction, breakdown and reformation of the filler-filler interaction and filler-rubber detachment would be the main causes of damping.

\section{Hysteresis}

The main effect plots of the S/N ratios for hysteresis loss are presented in Figure 10. The relationship between iron sand content and the $\mathrm{S} / \mathrm{N}$ ratio is approximately linear, with the amount of energy dissipated increasing with iron sand content up to $100 \mathrm{phr}$. The increase in energy 
dissipated could be attributed to interfacial friction, breakdown of filler aggregates to release trapped rubber to allow more viscous flow and filler rubber detachment and reformation. From Figure 10 (b) and (c), it can be seen that the particle size and magnetic field have minimal influence on hysteresis loss but the $\mathrm{S} / \mathrm{N}$ ratios at $45-56 \mu \mathrm{m}$ and $1000 \mathrm{mT}$ are the highest. It is also noted that the suggested optimum conditions to obtain highest hysteresis loss are similar to those for the optimum conditions when assessing influence of frequency on $\tan \delta$; the Taguchi method suggests that highest hysteresis loss and $\tan \delta$ could be obtained by using high iron sand content (100 phr and 70 phr, respectively) with particle size not being greatly influential (although 45-56 $\mu \mathrm{m}$ gave the highest for both hysteresis and $\tan \delta$ ). However, the suggested magnetic field during curing gives a contrary conclusion (1000 $\mathrm{mT}$ and $300 \mathrm{mT}$, respectively for hysteresis and $\tan \delta$ ) which could be due to the different mode of loading during testing (tensile versus shear). This suggests that energy absorption due to interaction between magnetic particles alignment is less efficient in a tensile mode compare with a shear mode using the DMA, which is not surprising, given that in tension, it is largely only the spacing increasing between chains, whereas in shear, the spacing within chain between the particles increases (see Figure 11).

Table 8 shows ANOVA results for hysteresis loss. Confidence levels for all factors are 98\% and higher. From the levels of contribution, it can be seen that the most influential factor by far is iron sand content followed by particle size ( $80.71 \%$ and $14.38 \%$, respectively). The influence of magnetic field was much less at $4.91 \%$.

Figure 12 shows stress-strain loops of the sample at the suggested optimum conditions (100 phr iron sand, 45-56 $\mu \mathrm{m}$ particle size and $1000 \mathrm{mT}$ ) and those for the highest hysteresis loss achieved previously (sample type 23) after a complete reversed stress cycle. As can be seen, the area of the hysteresis loop for the optimised sample is larger than sample type 23. The amount of energy loss for the optimised sample and sample type 23 are $160.96 \mathrm{~kJ} / \mathrm{m}^{3}$ and $154.61 \mathrm{~kJ} / \mathrm{m}^{3}$, respectively. This supports the optimum conditions suggested by the $\mathrm{S} / \mathrm{N}$ ratio and ANOVA. As the strain increases, the curvilinear part at the beginning of stretching is attributed to interfacial friction, breakdown of filler aggregates and filler rubber detachment and reformation and as the strain increases, the amount of energy dissipated increases, which is believed to be mainly 
dominated by the viscous flow in the rubber phase as reported in the literature ${ }^{35}$. As the strain increases, the cross sectional area of the tested samples reduces and the rubber molecular chains come closer to each other. Under further strain, the chains constrain each other, therefore they slide with respect to each other, resulting in further increased of dissipated energy. Upon removing the load, the rubber molecular chains do not completely regain their original configuration and the energy dissipated would be expected to have been converted into heat ${ }^{35,40}$.

\section{CONCLUSION}

In this work, iron sand and natural rubber MREs were manufactured and experiments were designed using the Taguchi method in order to assess the effect of iron sand content, iron sand particle size, and applied magnetic field during curing on the $\tan \delta$ (over a wide range of frequency, strain amplitude and temperature) and energy dissipated during cyclic loading. SEM micrographs revealed that isotropic MREs had homogeneous iron sand particle distribution and curing the materials under an applied magnetic field at elevated temperature resulted in the iron sand particles organising into chain-like columnar structures. For the effect of frequency on tan $\delta$, the Taguchi method suggested that the optimum conditions can be obtained by using $70 \mathrm{phr}$ iron sand, a 45-56 $\mu \mathrm{m}$ particle size and a $300 \mathrm{mT}$ magnetic field which was supported by experiment. It was found that iron sand had the greatest influence on $\tan \delta$ followed by particle size and magnetic field. The suggested optimum conditions to obtain highest hysteresis loss were similar to that for the optimum conditions when assessing influence of frequency on $\tan \delta$; the Taguchi method suggests that highest hysteresis loss could be obtained by using 100phr iron sand (slightly different to the $70 \mathrm{phr}$ iron sand for frequency) with particle size not being greatly influential (although 45-56 $\mu \mathrm{m}$ gave the highest for both hysteresis and tan $\delta$ ). However, the optimum magnetic field during curing is different for maximizing $\tan \delta$ and hysteresis loss (300 $\mathrm{mT}$ and $1000 \mathrm{mT}$, respectively) which could be due to the different mode of loading during testing (tensile versus shear). For the effect of strain amplitude on $\tan \delta$, none of the factors showed significant influence on $\tan \delta$ over a range of strain amplitude which could be attributed to the poor bonding between iron sand and rubber such that the weak interaction between the iron sand 
and natural rubber is fully disrupted at low strain amplitude and therefore, at high strain amplitude, the damping is dominated by the viscous flow of the rubber matrix. For the effect of temperature on $\tan \delta$, the optimum conditions suggested by the Taguchi method are $30 \mathrm{phr}$ iron sand, a 32-45 $\mu \mathrm{m}$ particle size and a $1000 \mathrm{mT}$. It was found that addition of iron sand and formation of magnetic particle chains constrained conformational changes of rubber molecular chains from taking part in relaxation process and therefore, increased the temperature at which the molecular chains start to mobilize, such that the width of the peak of $\tan \delta$ is increased. The different optimum conditions for different tests carried out herein would appear to be due to the relatively different amounts of energy absorbed by different degree that different mechanisms are involved with different loading conditions and at different frequencies and strain amplitudes.

\section{ACKNOWLEDGEMENTS}

The authors would like to thank for the support from the Polymer and Composite Research Group of the University of Waikato.

\section{REFERENCES}

1. Lakes, R. S., Journal of Composite Materials 36, 2872001.

2. Jerzy, K.; Daniel, L.; Rafal, M.; Piotr, Z., Smart Magnetic Composites (SMC); InTech: Poland, 2011.

3. Chokkalingam, R.; Rajasabai Senthur, P.; Mahendran, M., Journal of Composite Materials 45, 15452010.

4. Jerzy, K.; Michal, K.; Daniel, L., Smart Mater. Struct 20, 122011.

5. $\quad$ Chen, L.; Gong, X. L.; Li, W. H., Polymer Testing 27, 3402008.

6. $\quad$ Fuchs, A.; Zhang, Q.; Elkins, J.; Gordaninejad, F.; Evrensel, C., Journal of Applied Polymer Science 105, 24972007. 
7. $\quad$ Ginder, J., Proc. SPIE 3675, 1311999.

8. Lerner, A. A.; Cunefare, K. A., Journal of Intelligent Material Systems and Structures 19, 5512008.

9. Sun, T. L.; Gong, X. L.; Jiang, W. Q.; Li, J. F.; Xu, Z. B.; Li, W. H., Polymer Testing 27, 520 2008.

10. Wang, Y.; Hu, Y.; Deng, H.; Gong, X.; Zhang, P.; Jiang, W.; Chen, Z., Polymer Engineering \& Science 46, 2642006.

11. Lokander, M.; Stenberg, B., Polymer Testing 22, 6772003.

12. Lokander, M.; Stenberg, B., Polymer Testing 22, 2452003.

13. Carlson, J. D.; Jolly, M. R., Mechatronics 10, 5552000.

14. Blom, P.; Kari, L., Polymer Testing 24, 6562005.

15. Chen, L.; Gong, X.-I.; Jiang, W.-q.; Yao, J.-j.; Deng, H.-X.; Li, W.-h., Journal of Materials Science 42, 54832007.

16. Alberdi-Muniain, A.; Gil-Negrete, N.; Kari, L., Plastics, Rubber and Composites 41, 310 2012.

17. Sun, Y.; Zhou, X.; Liu, Y.; Zhao, G.; Jiang, Y., Materials Research Bulletin 45, 8782009.

18. Makled, M. H.; Matsui, T.; Tsuda, H.; Mabuchi, H.; El-Mansy, M. K.; Morii, K., Journal of Materials Processing Technology 160, 2292005.

19. Dobrzanski, L. A.; Tomiczek, A.; Tomiczek, B.; Slawska, A.; lesenchuk, O., Journal of Achievements in Materials and Manufacturing Engineering 37, 162009.

20. Bryan, K. R.; Robinson, A.; Briggs, R. M., Marine Geology 236, 452007.

21. Briggs, R. M.; Laurent, J. C.; Hume, T. M.; Swales, A. in AusIMM New Zealand Branch Annual Conference, New Zealand: 2009, p 41.

22. Montgomery, D. C., Design and analysis of experiments; Wiley: Michigan, 1997.

23. Arvidsson, M.; Gremyr, I. In Robust Design Methodology for Reliability; John Wiley \& Sons, Ltd, 2009.

24. Mitra, A., Wiley Interdisciplinary Reviews: Computational Statistics 3, 472.

25. Derakhshandeh, B.; Shojaei, A.; Faghihi, M., Journal of Applied Polymer Science 108, 38082008.

26. Bhattacharya, M.; Bhowmick, A. K., Wear 269, 152.

27. Roy, R. K., Design of Experiments Using The Taguchi Approach: 16 Steps to Product and Process Improvement; John Wiley \& Sons: New York, 2001.

28. Khimi, S. R.; Pickering, K. L., Journal of Applied Polymer Science 131, n/a.

29. Boczkowska, A.; Awietjan, S. F.; Pietrzko, S. a.; KurzydÅ,owski, K. J., Composites Part B: Engineering 43, 636.

30. Kari, L.; Blom, P., Plastics, Rubber and Composites 34, 3652005.

31. Shirazi, M.; Talma, A. G.; Noordermeer, J. W. M., Journal of Applied Polymer Science 128, 2255.

32. Han, J.; Shi, N.; Xie, L.; Ma, Y.; Wu, C., Journal of Macromolecular Science, Part B 49, 429.

33. Liu, Q. X.; Ding, X. B.; Zhang, H. P.; Yan, X., Journal of Applied Polymer Science 114, 26552009.

34. Kar, K. K.; Bhowmick, A. K., Polymer Engineering \& Science 38, 19271998.

35. Kucherskii, A. M., Polymer Testing 24, 7332005.

36. Arrighi, V.; McEwen, I. J.; Qian, H.; Serrano Prieto, M. B., Polymer 44, 62592003.

37. Yanceng, F.; Xinglong, G.; Shouhu, X.; Wei, Z.; Jian, Z.; Wanquan, J., Smart Mater. Struct. 20, 12011.

38. Hathaway, K.; Clark, A.; Teter, J., Metallurgical and Materials Transactions A 26, 2797 1995.

39. Rendek, M.; Lion, A., International Journal of Solids and Structures 47, 2918.

40. Ahankari, S. S.; Kar, K. K., Polymer Engineering \& Science 50, 871. 


\section{FIGURE CAPTIONS}

Figure 1 MRE structure: (a) isotropic MRE; and (b) anisotropic MRE.

Figure 2 Sketch of specially developed electromagnetic-heat coupled device.

Figure 3 SEM images of iron sand-natural rubber MREs: (a) isotropic MRE - $0 \mathrm{mT}$; (b) anisotropic MRE - $300 \mathrm{mT}$; (c) anisotropic MRE - $500 \mathrm{mT}$; (d) anisotropic MRE - $700 \mathrm{mT}$; (e) anisotropic MRE - 1000mT; and (f) interphase of iron sand-natural rubber matrix.

Figure 4 Main effect plots for $\mathrm{S} / \mathrm{N}$ ratio of $\tan \delta$ at $130 \mathrm{~Hz}$ (a) effect of iron sand content, (b) effect of iron sand particle size and (c) effect of magnetic field during curing.

Figure 5 (a) Tan $\delta$, (b) storage modulus $\left(G^{\prime}\right)$ and (c) loss modulus $\left(G^{\prime \prime}\right)$ versus frequency for the optimised sample and sample type 15.

Figure 6 Main effect plots for $\mathrm{S} / \mathrm{N}$ ratio of $\tan \delta$ at 3\% strain amplitude (a) effect of iron sand content, (b) effect of iron sand particle size and (c) effect of magnetic field during curing.

Figure 7 (a) Tan $\delta$, (b) storage modulus $\left(\mathrm{G}^{\prime}\right)$ and (c) loss modulus $\left(\mathrm{G}^{\prime \prime}\right)$ versus strain amplitude for the optimised sample and sample type 15 .

Figure 8 Main effect plots for $\mathrm{S} / \mathrm{N}$ ratio of $\tan \delta$ at $-35^{\circ} \mathrm{C}$ (a) effect of iron sand content, (b) effect of iron sand particle size and (c) effect of magnetic field during curing.

Figure 9 Tan $\delta$ versus temperature for natural rubber, the optimised sample and sample 17.

Figure 10 Main effect plots for $\mathrm{S} / \mathrm{N}$ ratio of hysteresis loss (a) effect of iron sand content, (b) effect of iron sand particle size and (c) effect of magnetic field during curing.

Figure 11 Comparison of influence of loading types on particle separation, (a) tensile mode, (b) shear mode.

Figure 12 Hysteresis loops of optimised sample and sample 23.

\section{TABLE CAPTIONS}

Table 1 Masterbatch formulation

Table 2 Experimental control factors and their respective levels

Table 3 Experimental layout of an L25 orthogonal array according to the Taguchi method

Table 4 Tan $\delta$ and hysteresis loss used to calculate $\mathrm{S} / \mathrm{N}$ ratios and ANOVA, highest value shown in bold

Table 5 ANOVA results for the effect of frequency on $\tan \delta$

Table 6 ANOVA results for the effect of $\tan \delta$ on strain amplitude

Table 7 ANOVA results for effect of temperature on $\tan \delta$

Table 8 ANOVA results for hysteresis loss 

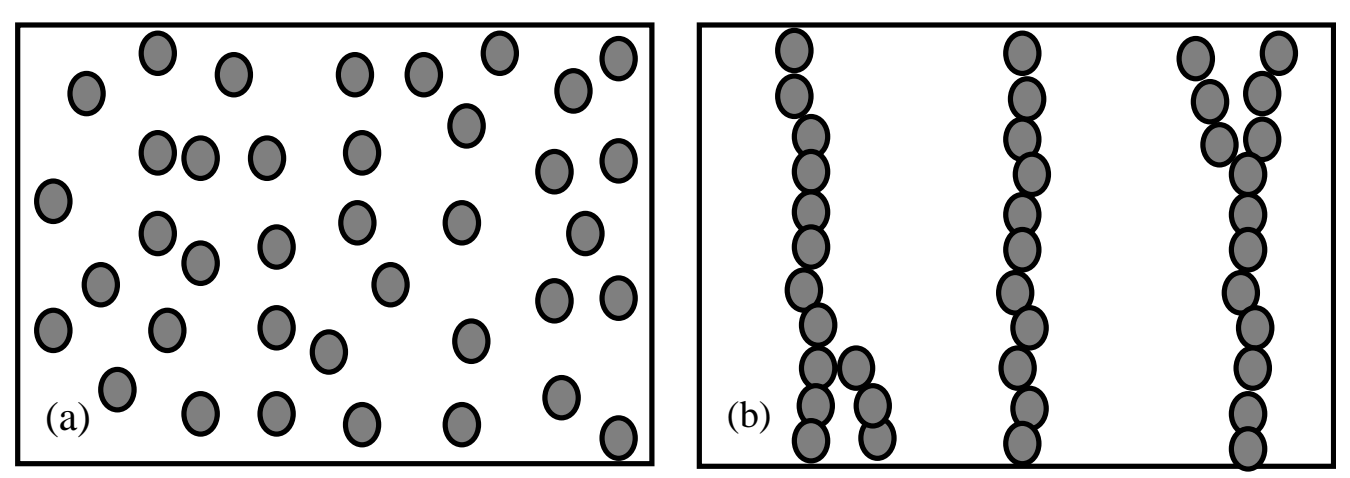

Figure 1 MRE structure: (a) isotropic MRE; and (b) anisotropic MRE.

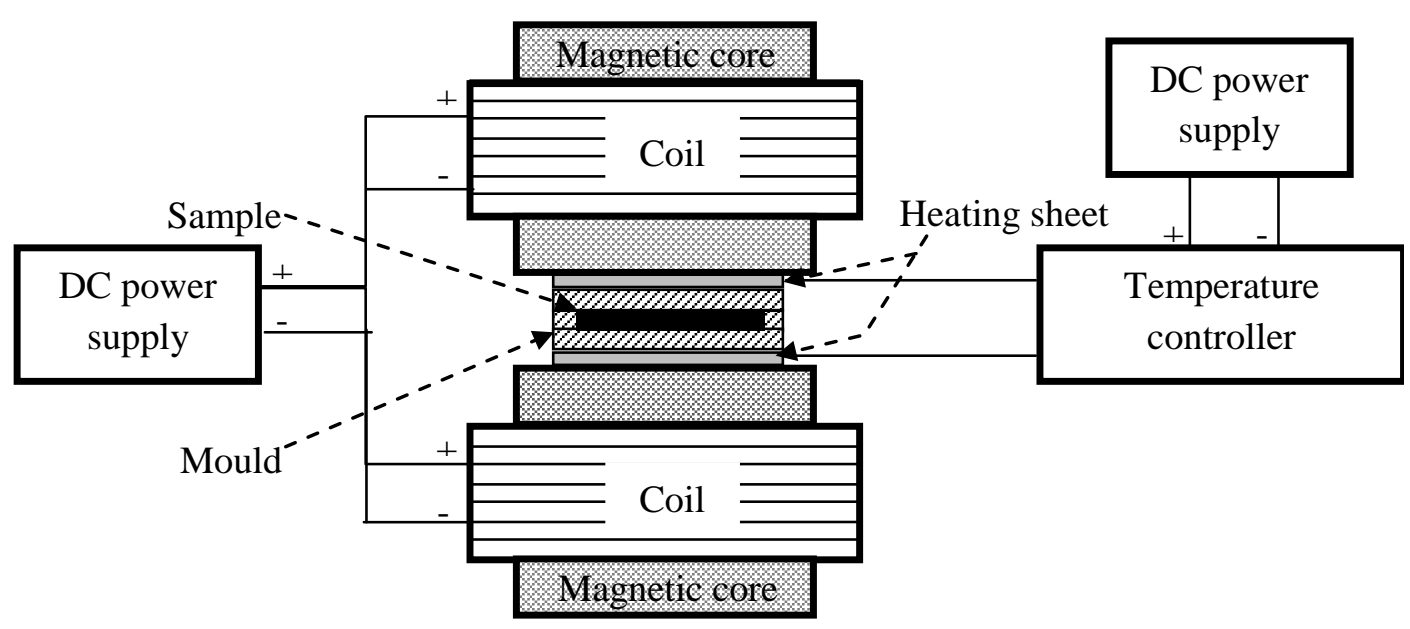

Figure 2 Sketch of specially developed electromagnetic-heat coupled device. 

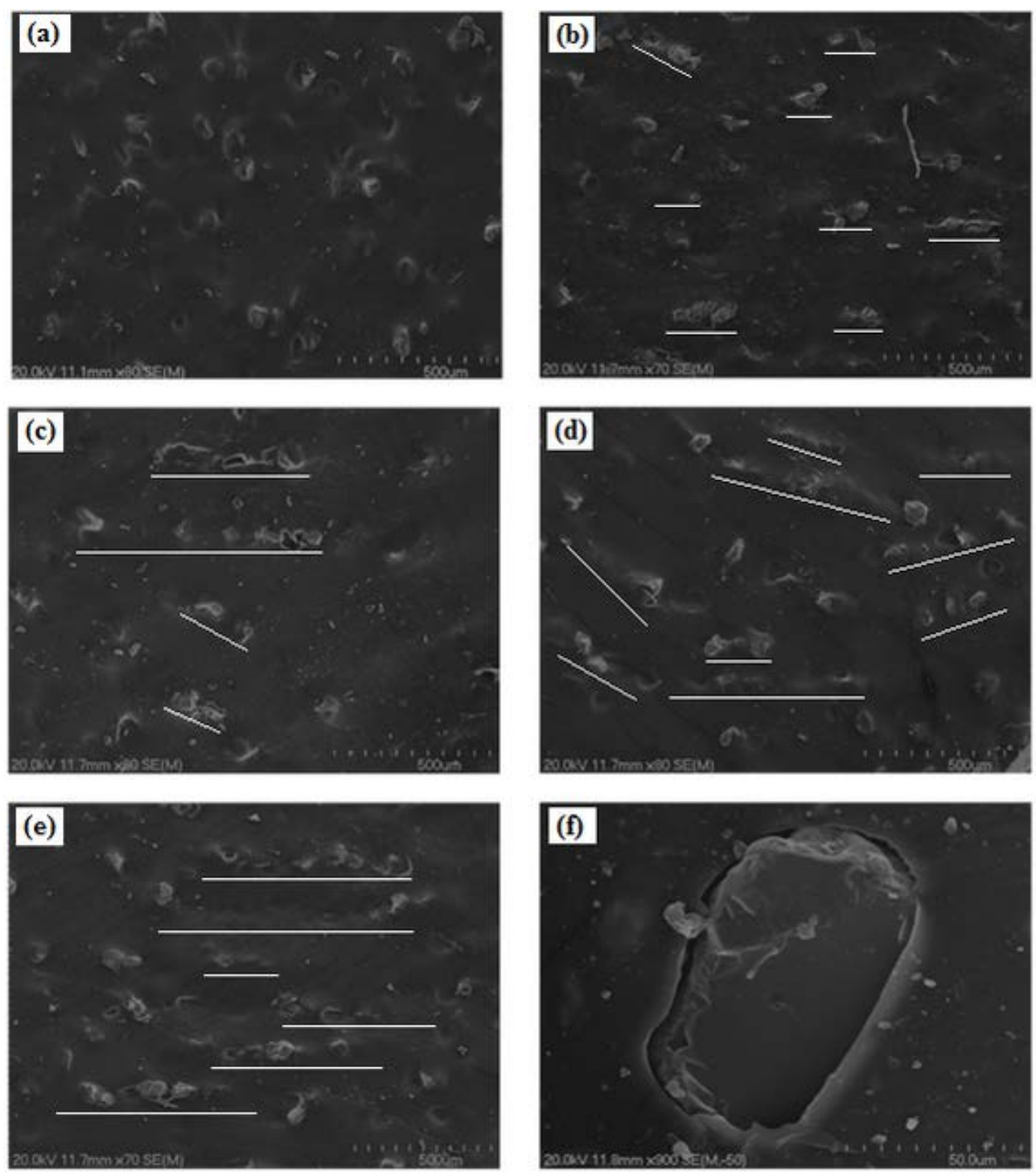

Figure 3 SEM images of iron sand-natural rubber MREs: (a) isotropic MRE - $0 \mathrm{mT}$; (b) anisotropic MRE - $300 \mathrm{mT}$; (c) anisotropic MRE - $500 \mathrm{mT}$; (d) anisotropic MRE - $700 \mathrm{mT}$; (e) anisotropic MRE - 1000mT; and (f) interphase of iron sand-natural rubber matrix. 

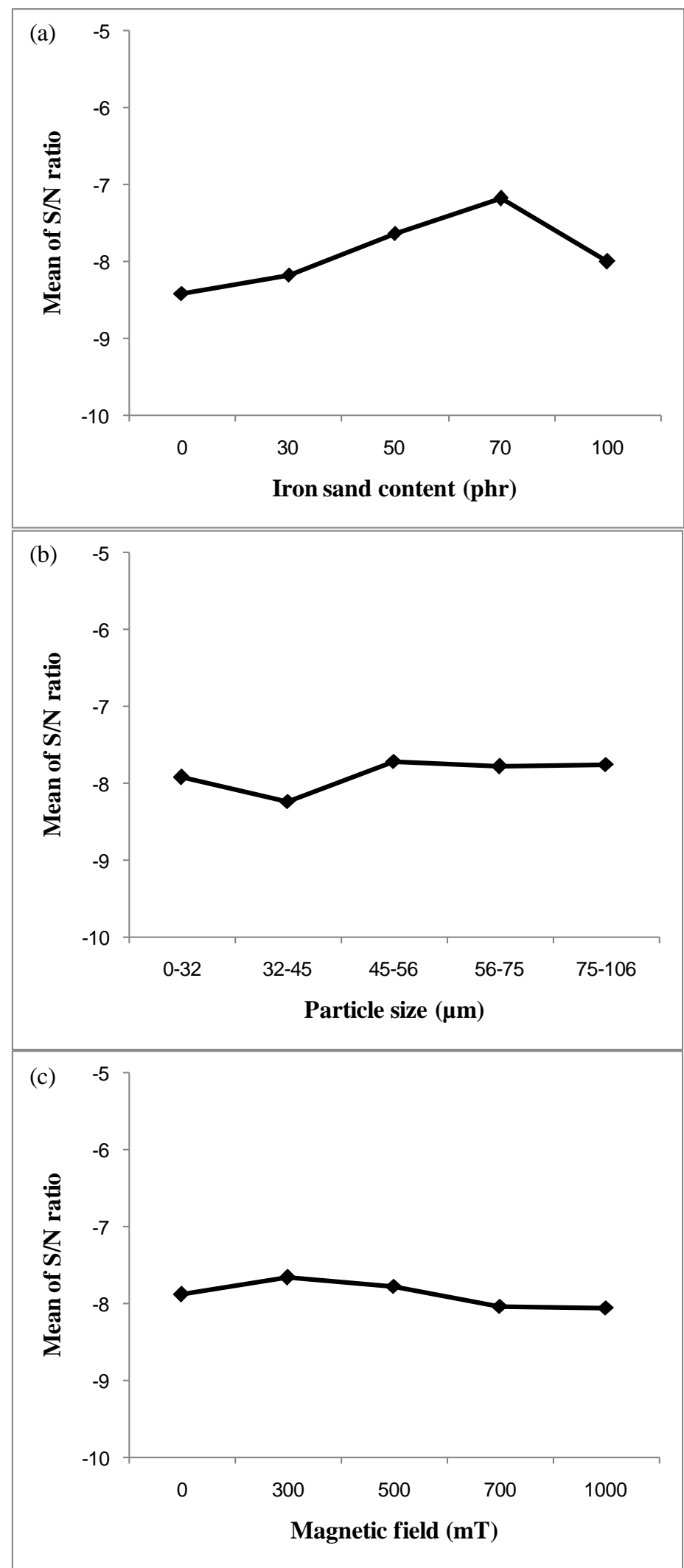

Figure 4 Main effect plots for $\mathrm{S} / \mathrm{N}$ ratio of $\tan \delta$ at $130 \mathrm{~Hz}$ (a) effect of iron sand content, (b) effect of iron sand particle size and (c) effect of magnetic field during curing. 


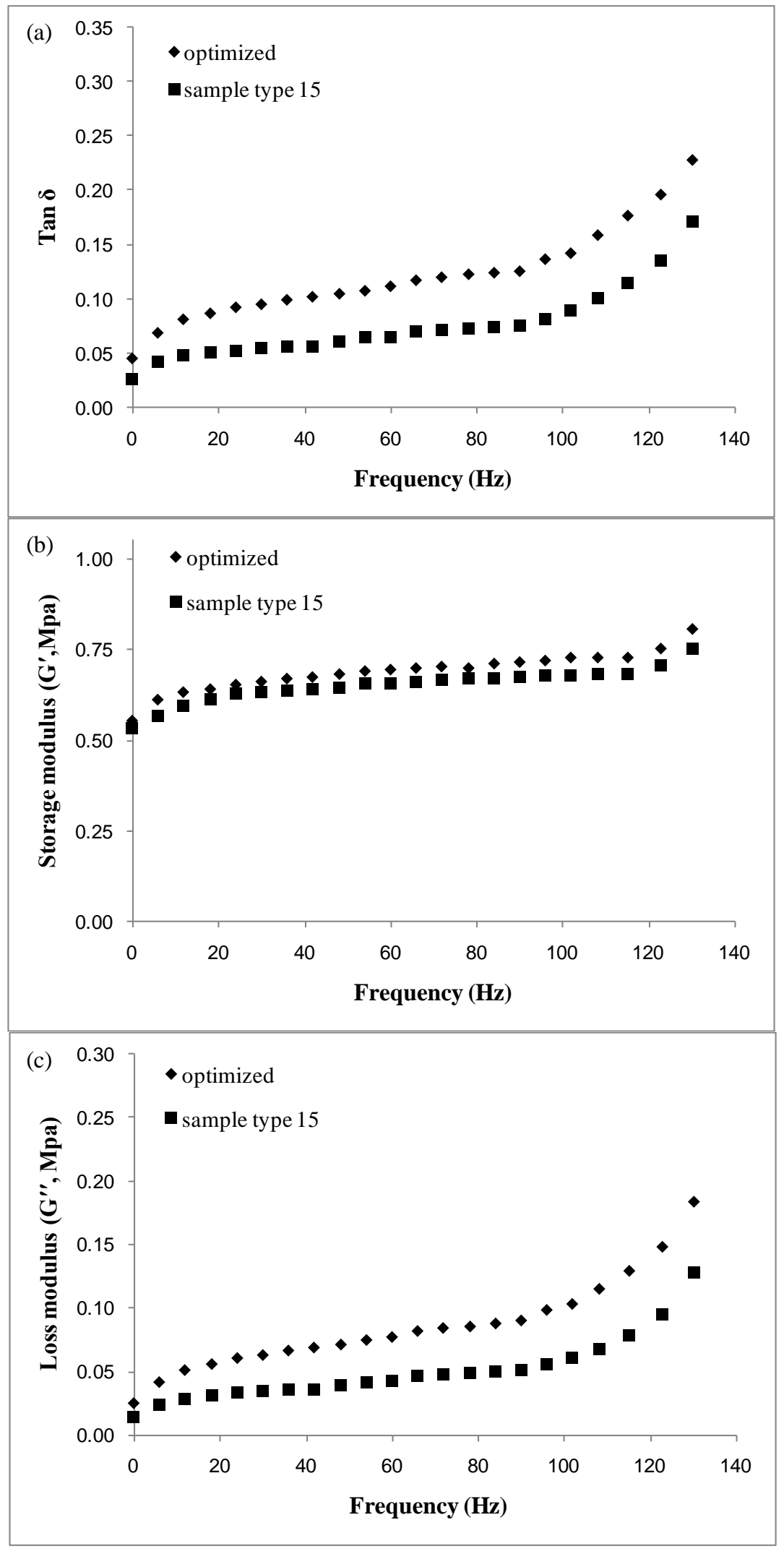

Figure 5 (a) Tan $\delta$, (b) storage modulus $\left(\mathrm{G}^{\prime}\right)$ and (c) loss modulus $\left(\mathrm{G}^{\prime \prime}\right)$ versus frequency for the optimised sample and sample type 15. 

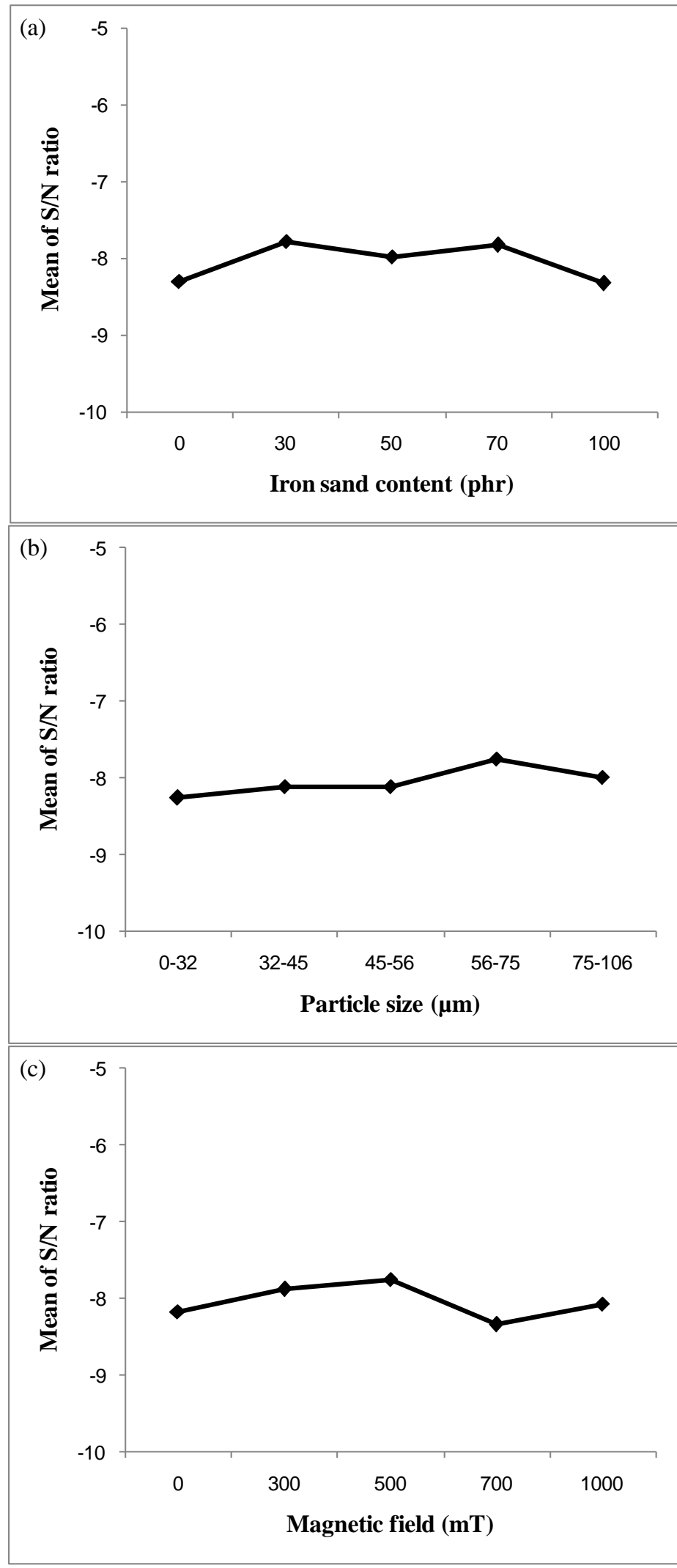

Figure 6 Main effect plots for $\mathrm{S} / \mathrm{N}$ ratio of $\tan \delta$ at 3\% strain amplitude (a) effect of iron sand content, (b) effect of iron sand particle size and (c) effect of magnetic field during curing. 

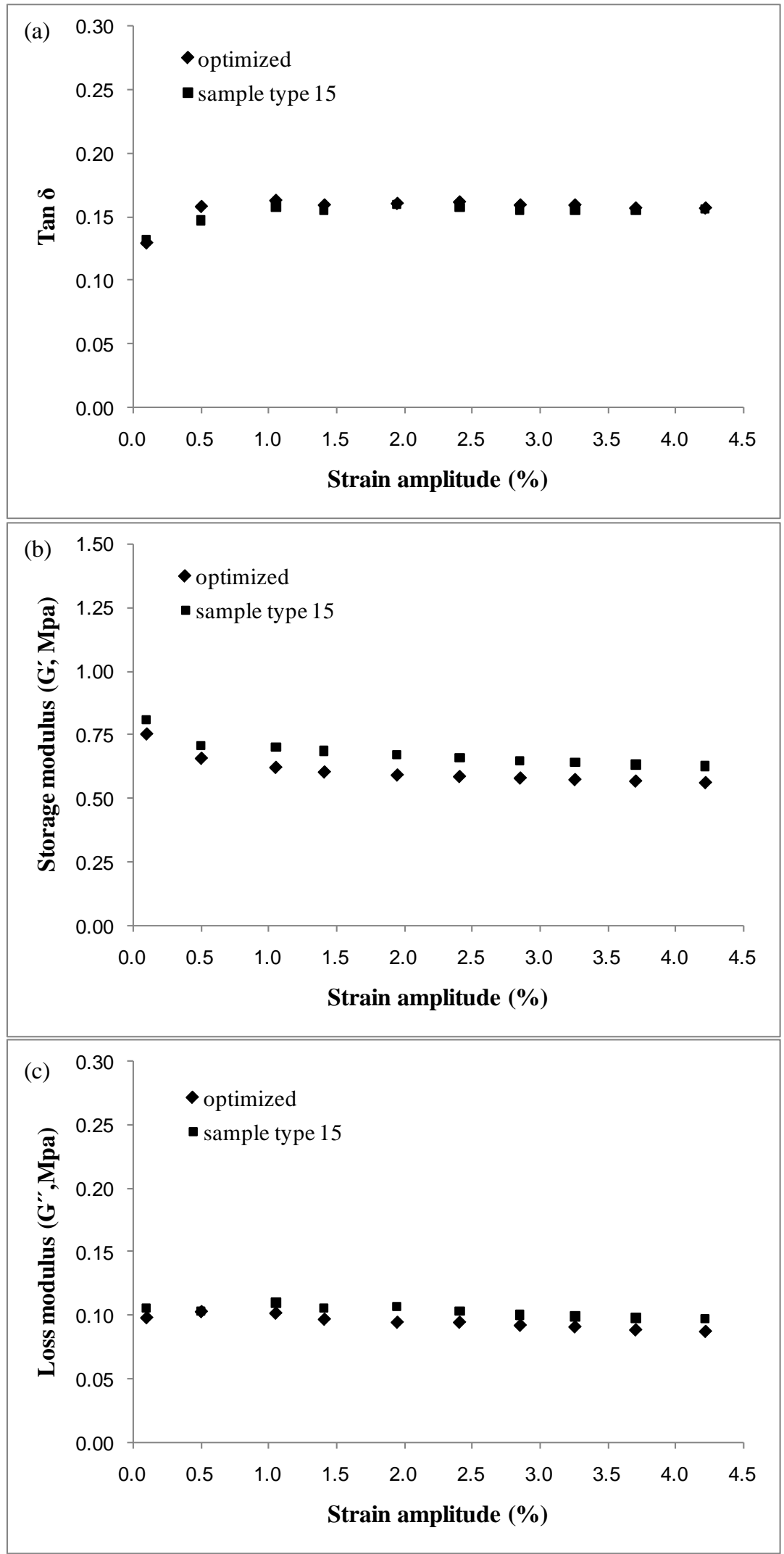

Figure 7 (a) Tan $\delta$, (b) storage modulus $\left(\mathrm{G}^{\prime}\right)$ and (c) loss modulus $\left(\mathrm{G}^{\prime \prime}\right)$ versus strain amplitude for the optimised sample and sample type 15. 

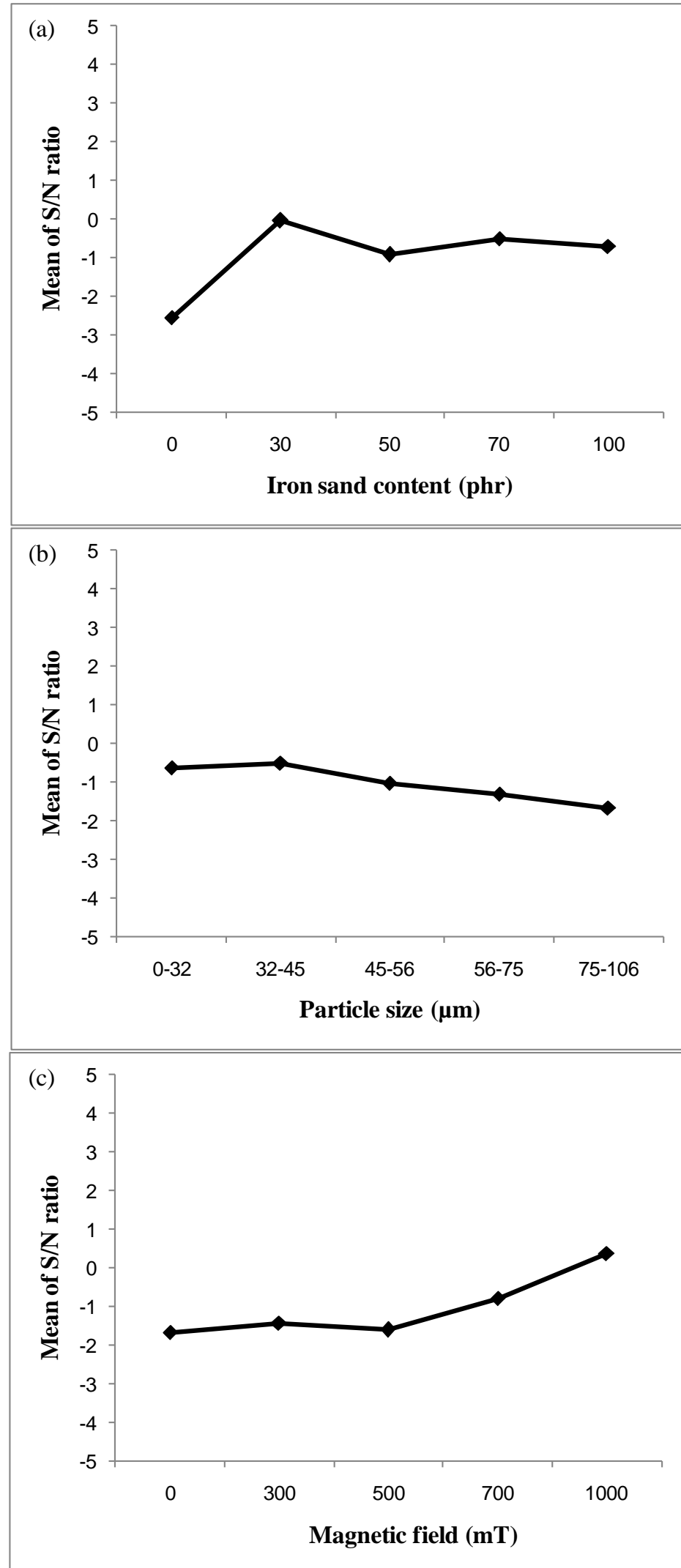

Figure 8 Main effect plots for $\mathrm{S} / \mathrm{N}$ ratio of $\tan \delta$ at $-35^{\circ} \mathrm{C}$ (a) effect of iron sand content, (b) effect of iron sand particle size and (c) effect of magnetic field during curing. 


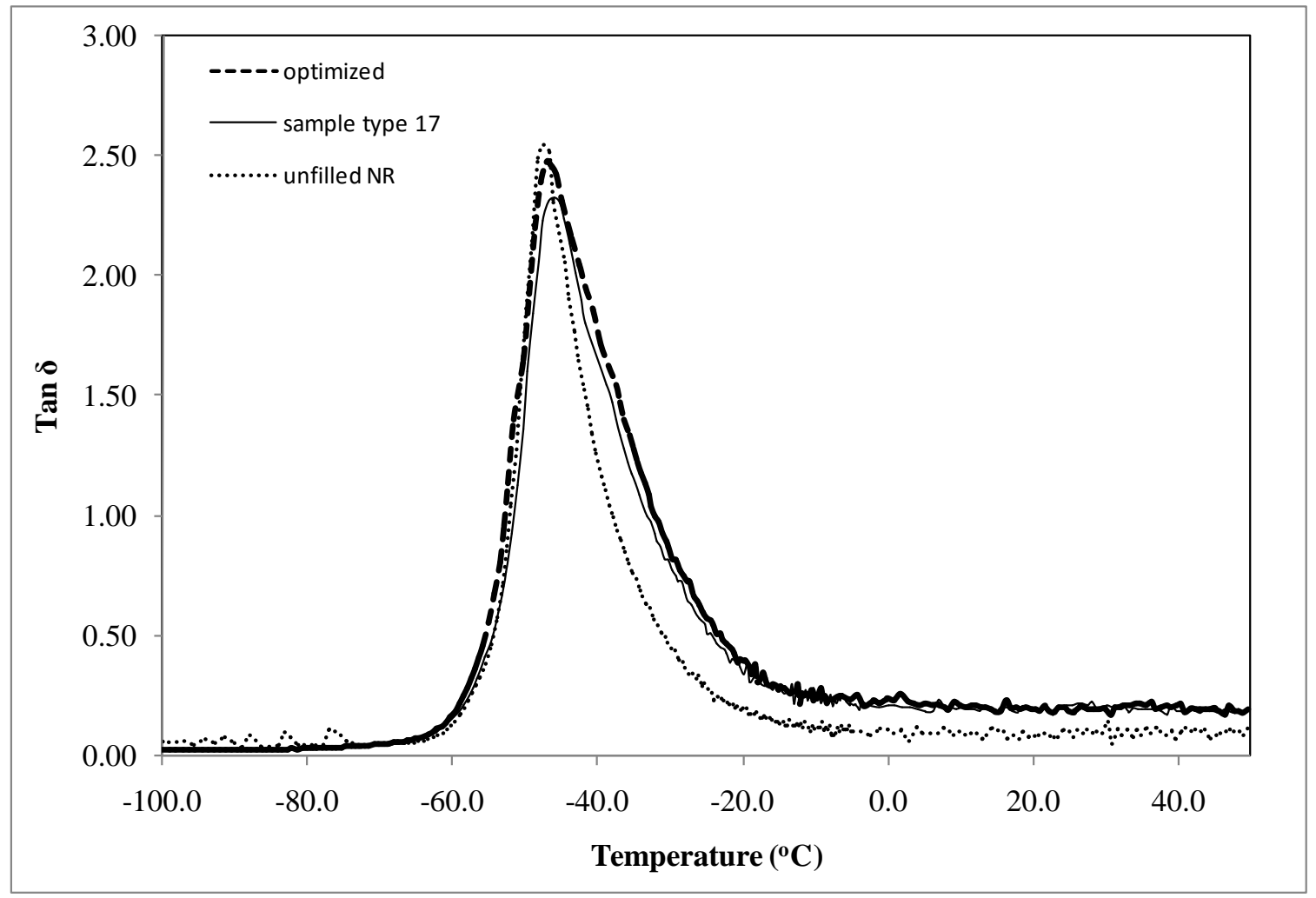

Figure 9 Tan $\delta$ versus temperature for natural rubber, the optimised sample and sample 17. 

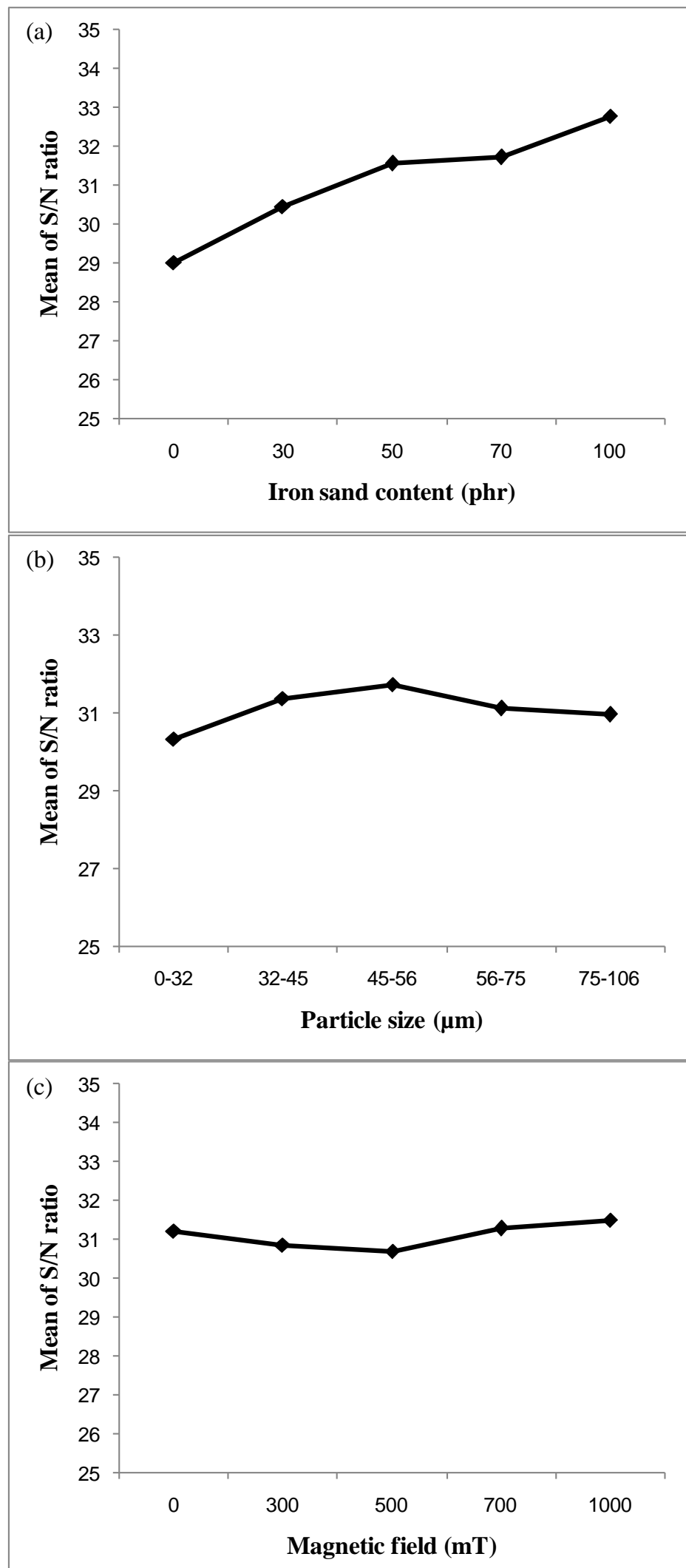

Figure 10 Main effect plots for $\mathrm{S} / \mathrm{N}$ ratio of hysteresis loss (a) effect of iron sand content, (b) effect of iron sand particle size and (c) effect of magnetic field during curing. 


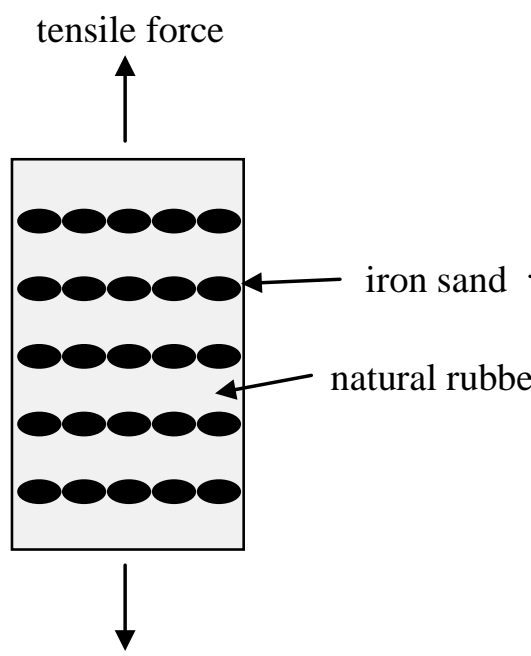

(a)

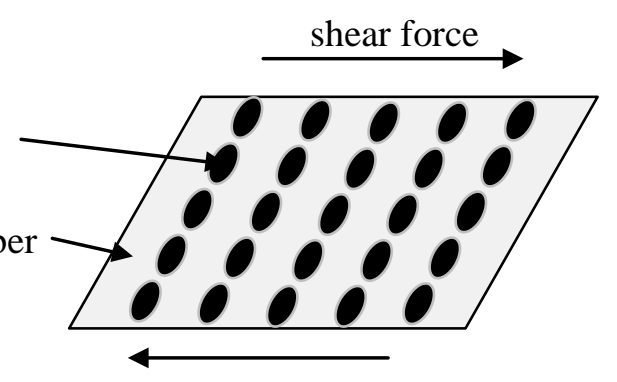

(b)

Figure 11 Comparison of influence of loading types on particle separation, (a) tensile mode, (b) shear mode.

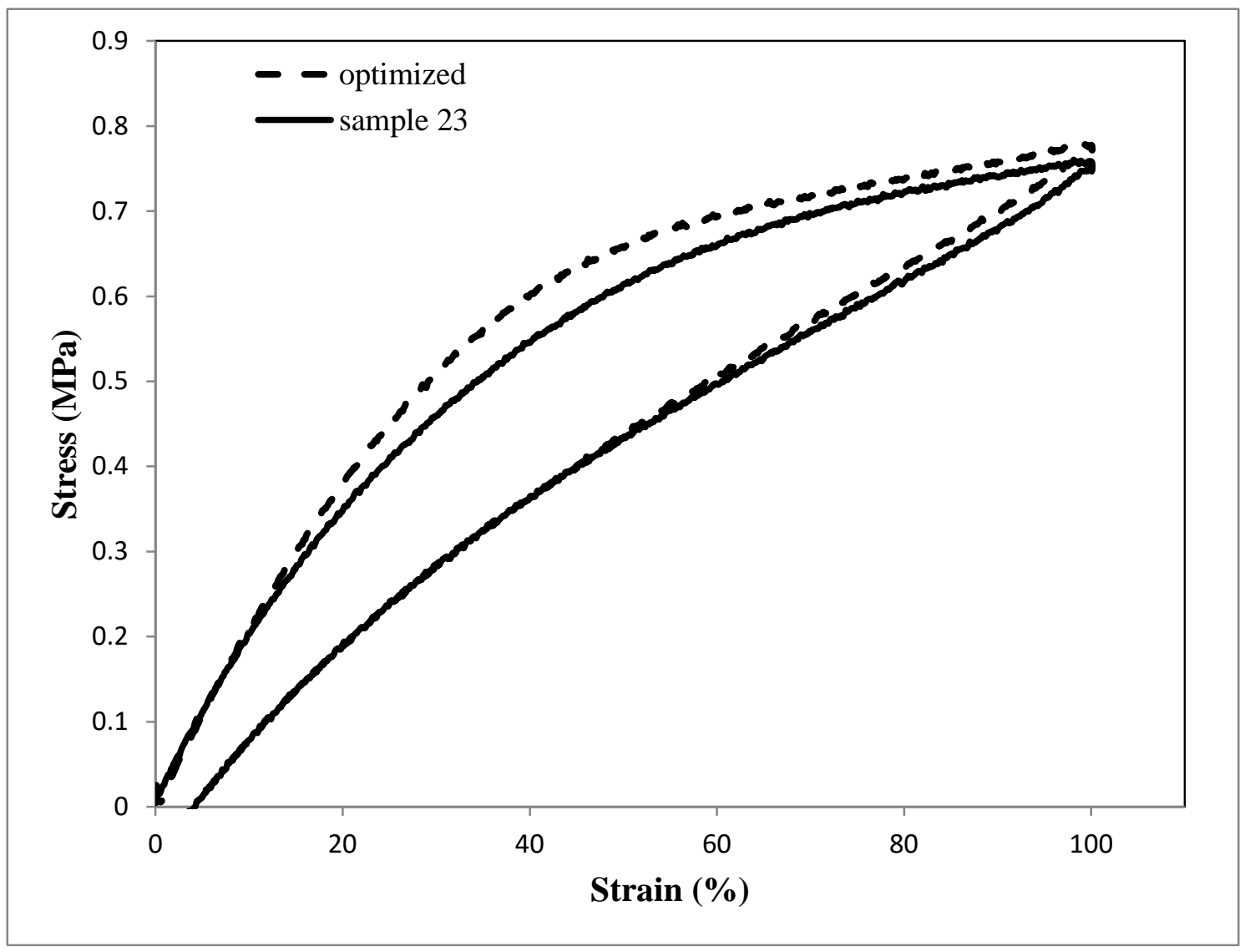

Figure 12 Hysteresis loops of optimised sample and sample 23. 
Table 1 Masterbatch formulation

\begin{tabular}{llc}
\hline Materials & Function & phr* \\
\hline Natural Rubber & raw material/matrix & 100 \\
ZnO & activator/peptiser & 5 \\
Stearic Acid & activator/peptiser & 1 \\
CBS & accelerator & 2 \\
TMTD & accelerator & 1 \\
Paraffin Oil & plasticiser & 2 \\
Naphthenic Oil & plasticiser & 3 \\
Sulphur & crosslinking agent & 1.5 \\
\hline *parts per hundred rubber & &
\end{tabular}

Table 2 Experimental control factors and their respective levels

\begin{tabular}{lccccccc}
\hline Factors & Symbol & Unit & Level 1 & Level 2 & Level 3 & Level 4 & Level 5 \\
\hline Iron sand content & $\mathrm{I}$ & $\mathrm{phr}$ & 0 & 30 & 50 & 70 & 100 \\
Particle size & $\mathrm{P}$ & $\mu \mathrm{m}$ & $0-32$ & $32-45$ & $45-56$ & $56-75$ & $75-106$ \\
Magnetic field & $\mathrm{M}$ & $\mathrm{mT}$ & 0 & 300 & 500 & 700 & 1000 \\
\hline
\end{tabular}

${ }^{*}$ phr=part per hudred rubber, ${ }^{*} \mu \mathrm{m}=$ micrometer, ${ }^{*} \mathrm{mT}=$ miliTesla 
Table 3 Experimental layout of an L25 orthogonal array according to the Taguchi method

\begin{tabular}{|c|c|c|c|}
\hline \multirow{2}{*}{$\begin{array}{c}\text { Sample } \\
\text { type }\end{array}$} & \multicolumn{3}{|c|}{ Factors and their levels } \\
\hline & $\mathbf{I}$ & $\mathbf{P}$ & $\mathbf{M}$ \\
\hline 1 & 1 & 1 & 1 \\
\hline 2 & 1 & 2 & 2 \\
\hline 3 & 1 & 3 & 3 \\
\hline 4 & 1 & 4 & 4 \\
\hline 5 & 1 & 5 & 5 \\
\hline 6 & 2 & 1 & 2 \\
\hline 7 & 2 & 2 & 3 \\
\hline 8 & 2 & 3 & 4 \\
\hline 9 & 2 & 4 & 5 \\
\hline 10 & 2 & 5 & 1 \\
\hline 11 & 3 & 1 & 3 \\
\hline 12 & 3 & 2 & 4 \\
\hline 13 & 3 & 3 & 5 \\
\hline 14 & 3 & 4 & 1 \\
\hline 15 & 3 & 5 & 2 \\
\hline 16 & 4 & 1 & 4 \\
\hline 17 & 4 & 2 & 5 \\
\hline 18 & 4 & 3 & 1 \\
\hline 19 & 4 & 4 & 2 \\
\hline 20 & 4 & 5 & 3 \\
\hline 21 & 5 & 1 & 5 \\
\hline 22 & 5 & 2 & 1 \\
\hline 23 & 5 & 3 & 2 \\
\hline 24 & 5 & 4 & 3 \\
\hline 25 & 5 & 5 & 4 \\
\hline
\end{tabular}


Table 4 Tan $\delta$ and hysteresis loss used to calculate $\mathrm{S} / \mathrm{N}$ ratios and ANOVA, highest value shown in bold

\begin{tabular}{|c|c|c|c|c|}
\hline $\begin{array}{c}\text { Sample } \\
\text { type }\end{array}$ & $\begin{array}{l}\text { Maximum } \tan \delta \\
\text { over } 0.01-130 \mathrm{~Hz} \\
(130 \mathrm{~Hz})^{* a}\end{array}$ & $\begin{array}{c}\text { Tan } \delta \text { at plateau } \\
\text { over } 0.1-4.5 \% \\
\text { strain amplitude } \\
(3 \%)^{* b}\end{array}$ & $\begin{array}{l}\text { Tan } \delta \text { in transition } \\
\text { region of }-47-0^{\circ} \mathrm{C} \\
\quad\left(-35^{\circ} \mathrm{C}\right) * \mathrm{c}\end{array}$ & $\begin{array}{r}\text { Hysteresis loss } \\
\left(\mathrm{kJ} / \mathrm{m}^{3}\right)\end{array}$ \\
\hline 1 & 0.093 & 0.098 & 0.758 & 31.59 \\
\hline 2 & 0.093 & 0.098 & 0.749 & 31.96 \\
\hline 3 & 0.097 & 0.099 & 0.720 & 31.71 \\
\hline 4 & 0.096 & 0.098 & 0.758 & 31.72 \\
\hline 5 & 0.095 & 0.098 & 0.744 & 32.44 \\
\hline 6 & 0.111 & 0.103 & 1.082 & 39.04 \\
\hline 7 & 0.078 & 0.129 & 0.870 & 52.46 \\
\hline 8 & 0.131 & 0.112 & 0.946 & 69.98 \\
\hline 9 & 0.095 & 0.137 & 1.142 & 55.11 \\
\hline 10 & 0.112 & 0.113 & 0.958 & 49.46 \\
\hline 11 & 0.118 & 0.099 & 0.881 & 45.55 \\
\hline 12 & 0.114 & 0.107 & 1.025 & 94.15 \\
\hline 13 & 0.125 & 0.110 & 1.128 & 110.92 \\
\hline 14 & 0.103 & 0.090 & 0.676 & 96.41 \\
\hline 15 & 0.171 & 0.155 & 0.670 & 57.10 \\
\hline 16 & 0.133 & 0.104 & 0.913 & 57.58 \\
\hline 17 & 0.112 & 0.098 & 1.216 & 119.48 \\
\hline 18 & 0.158 & 0.118 & 0.843 & 95.26 \\
\hline 19 & 0.161 & 0.134 & 0.952 & 70.09 \\
\hline 20 & 0.169 & 0.130 & 0.842 & 75.51 \\
\hline 21 & 0.114 & 0.095 & 1.061 & 100.05 \\
\hline 22 & 0.113 & 0.098 & 0.920 & 99.29 \\
\hline 23 & 0.103 & 0.090 & 0.851 & 154.61 \\
\hline 24 & 0.151 & 0.148 & 0.851 & 104.10 \\
\hline 25 & 0.078 & 0.071 & 0.946 & 133.34 \\
\hline
\end{tabular}

${ }^{* a}$ Strain amplitude $=0.5 \%$

${ }^{* b}$ Frequency $=100 \mathrm{~Hz}$

*c Strain amplitude $=0.5 \%$ and frequency $=1 \mathrm{~Hz}$ 
Table 5 ANOVA results for the effect of frequency on $\tan \delta$

\begin{tabular}{lcccc}
\hline Factor & $\begin{array}{c}\text { Sum of } \\
\text { squares }\end{array}$ & $\begin{array}{c}\text { Degrees of } \\
\text { freedom }\end{array}$ & $\begin{array}{c}\text { \% confidence } \\
\text { level }\end{array}$ & \% contribution \\
\hline Iron sand content $(\mathrm{phr})$ & 0.024 & 4 & 99.9 & 72.73 \\
Particle size $(\mu \mathrm{m})$ & 0.005 & 4 & 99 & 15.15 \\
Magnetic field $(\mathrm{mT})$ & 0.004 & 4 & 97 & 12.12 \\
\hline
\end{tabular}

Table 6 ANOVA results for the effect of $\tan \delta$ on strain amplitude

\begin{tabular}{lcccc}
\hline Factor & $\begin{array}{c}\text { Sum of } \\
\text { squares }\end{array}$ & $\begin{array}{c}\text { Degrees of } \\
\text { freedom }\end{array}$ & $\begin{array}{c}\text { \% confidence } \\
\text { level }\end{array}$ & \% contribution \\
\hline Iron sand content $(\mathrm{phr})$ & 0.005 & 4 & 99.9 & 35.71 \\
Particle size $(\mu \mathrm{m})$ & 0.004 & 4 & 99.9 & 28.57 \\
Magnetic field $(\mathrm{mT})$ & 0.005 & 4 & 99.9 & 35.71 \\
\hline
\end{tabular}

Table 7 ANOVA results for effect of temperature on $\tan \delta$

\begin{tabular}{lcccc}
\hline Factor & $\begin{array}{c}\text { Sum of } \\
\text { squares }\end{array}$ & $\begin{array}{c}\text { Degrees of } \\
\text { freedom }\end{array}$ & $\begin{array}{c}\text { \% confidence } \\
\text { level }\end{array}$ & \% contribution \\
\hline Iron sand content $(\mathrm{phr})$ & 0.185 & 4 & 99 & 48.15 \\
Particle size $(\mu \mathrm{m})$ & 0.035 & 4 & 70 & 9.22 \\
Magnetic field $(\mathrm{mT})$ & 0.164 & 4 & 99 & 42.62 \\
\hline
\end{tabular}


Table 8 ANOVA results for hysteresis loss

\begin{tabular}{lcccc}
\hline Factor & $\begin{array}{c}\text { Sum of } \\
\text { squares }\end{array}$ & $\begin{array}{c}\text { Degrees of } \\
\text { freedom }\end{array}$ & $\begin{array}{c}\text { \% confidence } \\
\text { level }\end{array}$ & \% contribution \\
\hline Iron sand content $(\mathrm{phr})$ & 43038.6 & 4 & 99.9 & 80.71 \\
Particle size $(\mu \mathrm{m})$ & 7669.1 & 4 & 99.9 & 14.38 \\
Magnetic field $(\mathrm{mT})$ & 2616.7 & 4 & 98 & 4.91 \\
\hline
\end{tabular}

